„TURYZM” 1995, t. 5, z. 2

Jerzy Wyrzykowski

\title{
MIEJSCE POLSKI NA RYNKU TURYSTYCZNYM EUROPY ŚRODKOWEJ
} I WSCHODNIEJ

\section{LA PLACE DE LA POLOGNE SUR LE MARCHÉ TOURISTIQUE DE L'EUROPE CENTRALE ET DE L'EST}

\section{POLAND ON THE TOURIST MARKET OF CENTRAL AND EASTERN EUROPE}

Przełom lat 80. i 90. to okres wielkich przemian politycznych, społecznych i gospodarczych w Europie Środkowej i Wschodniej. Dotyczą one także gospodarki turystycznej.

Po 1945 r. we wszystkich krajach socjalistycznych tego regionu (poza byłą Jugosławią) dominował model turystyki socjalnej, zaś turystyka krajowa stanowiła główną część ruchu turystycznego. Wyjazdy zagraniczne były przez długi czas ograniczane i w głównej mierze dotyczyły krajów „bloku socjalistycznego". Rozwój zagranicznej turystyki przyjazdowej, któremu większą uwage poświęciły takie kraje jak Węgry, dawna Czechosłowacja, Bułgaria, a także w pewnym okresie Rumunia, traktowany był głównie jako czynnik równoważący bilans dewizowy. W grupie krajów Europy Środkowej i Wschodniej Polska i Niemiecka Republika Demokratyczna należały do krajów o stosunkowo najsłabiej rozwiniętym „przemyśle turystycznym”.

Zmiany polityczne, społeczne i gospodarcze ostatnich lat w krajach Europy Środkowej i Wschodniej, wprowadzenie zasad gospodarki wolnorynkowej do gospodarki turystycznej, pozwalają już traktować ten region jako część europejskiego rynku turystycznego i uznać poszczególne kraje jako znaczące cele turystyki zagranicznej, a także jako potencjalne źródła międzynarodowego ruchu turystycznego.

Do krajów o największym potencjale powierzchniowym i ludnościowym należą: Rosja (Federacja Rosyjska), Ukraina i Polska (tab. I). Najwyższy dochód roczny na osobę posiadają mieszkańcy Węgier i Czech (tab. I), najlepsze wyniki gospodarcze w ostatnich latach osiaggnęła Polska. 
Kraje Europy Środkowej i Wschodniej

T a b e l a I

Les pays de l'Europe Centrale et de l'Est

\begin{tabular}{|l|r|r|c|}
\hline \multicolumn{1}{|c|}{ Kraj } & $\begin{array}{r}\text { Powierzchnia } \\
\text { w km² }\end{array}$ & $\begin{array}{c}\text { Ludność w tys. } \\
\text { w 1991 r. }\end{array}$ & $\begin{array}{c}\text { Dochód narodowy } \\
\text { na osobę (USD) }\end{array}$ \\
\hline Bułgaria & 110912 & 8982 & 2210 \\
dawna Czechoslowacja: & 79000 & 10400 & \\
Czechy & 49000 & 5300 &. \\
Slowacja & 93032 & 10344 & 2780 \\
Węgry & 323250 & 38244 & 1700 \\
Polska & 237500 & 23193 & 1640 \\
Rumunia & 207600 & & \\
dawny ZSRR: & 45100 & 1593 & $\cdot$ \\
Białoruś & 64500 & $2687^{*}$ & $\cdot$ \\
Estonia & 65200 & 3741 & $\cdot$ \\
Lotwa & 33700 & 4363 & $\cdot$ \\
Litwa & 17075400 & $148041^{*}$ &. \\
Mołdawia & 60700 & $51839^{*}$ &. \\
Rosja (fed. Rosji) & & & \\
Ukraina &
\end{tabular}

* Dane za rok 1990.

Ź r ó d ł o: Statistical Yearbook 1992, United Nations, 1994; Der Fisher Welt Almanach 1993, Foscher Taschenbuch Verlag; Philip's Wordl Handbook, Country by Country, 1993.

Poziom rozwoju turystyki zagranicznej w krajach Europy Środkowej i Wschodniej ilustruje liczba odwiedzających (przekroczenia granicy, tab. II), liczba turystów (tab. III), liczba noclegów udzielonych turystom zagranicznym (tab. IV)

T a b e la II

Odwiedzający (z zagranicy) i liczba przekroczeń granicy w krajach Europy Środkowej i Wschodniej (w tys.)

Les arrivants (de l'étranger) et le nombre des personnes ayant franchi la frontière dans les pays de l'Europe Centrale et de l'Est (en mille)

\begin{tabular}{|l|r|r|r|r|r|c|}
\hline \multirow{2}{*}{ Kraj } & \multicolumn{6}{c|}{ Rok } \\
\cline { 2 - 7 } & \multicolumn{1}{|c|}{1988} & \multicolumn{1}{|c|}{1989} & \multicolumn{1}{c|}{1990} & \multicolumn{1}{c|}{1991} & \multicolumn{1}{c|}{1992} & 1993 \\
\hline Bulgaria & 8295 & 8221 & 10330 & 6818 & 6124 &. \\
dawna Czechosłowacja & 24593 & 29683 & 46586 & 64801 & 83477 &. \\
Węgry & 17965 & 24919 & 37632 & 33265 & 33490 &. \\
Polska & 6196 & 8233 & 18211 & 36846 & 49015 & 60951 \\
Rumunia & 5514 & 4852 & 6533 & 5360 & 6280 &. \\
dawny ZSRR & 6007 & 7792 & 7204 & 6895 & 6900 &. \\
\hline
\end{tabular}

Ż r ó d 1 o: Yearbook of Tourism Statistics 1994, WTO. 
T a b e l a III

Przyjazdy turystów z zagranicy do krajów Europy Środkowej i Wschodniej (w tys.)

Les arrivées des touristes de l'étranger dans les pays de l'Europe Centrale et de l'Est (en mille)

\begin{tabular}{|l|l|r|r|r|r|r|r|r|}
\hline \multirow{2}{*}{ Kraj } & \multicolumn{7}{|c|}{ Rok } \\
\cline { 2 - 10 } & 1985 & \multicolumn{1}{|c|}{1986} & \multicolumn{1}{|c|}{1987} & \multicolumn{1}{c|}{1988} & \multicolumn{1}{c|}{1989} & 1990 & 1991 & 1992 \\
\hline Butgaria & 3427 & 3506 & 3604 & 3967 & 4316 & 4500 & 4000 & 3750 \\
dawna Czechoslowacja & 4869 & 5330 & 6126 & 6886 & 8036 & 8100 & 8200 & 8000 \\
Węgry & 9124 & 10613 & 11826 & 10563 & 14490 & 20510 & 21860 & 20188 \\
Polska & 2749 & 2500 & 2484 & 2495 & 3293 & 3400 & 3800 & 4000 \\
Rumunia & 4772 & 4535 & 5142 & 5514 & 4892 & 6533 & 5360 & 6280 \\
dawny ZSRR & 4340 & 4309 & 5246 & 6007 & 7752 & 7204 & 6895 & 6900 \\
\hline
\end{tabular}

Ź r ó d 1 o: Yearbook of Tourism Statistics 1994, WTO.

T a b e l a IV

Noclegi udzielone turystom z zagranicy w bazie noclegowej ogółem w krajach Europy Środkowej i Wschodniej (w tys.)

Le total des nuits passées par les touristes étrangers dans les bases de couchage dans les pays de l'Europe Centrale et de l'Est (en mille)

\begin{tabular}{|l|r|r|r|r|r|}
\hline \multirow{2}{*}{ Kraj } & \multicolumn{5}{|c|}{ Rok } \\
\cline { 2 - 6 } & 1988 & 1989 & 1990 & \multicolumn{1}{c|}{1991} & \multicolumn{1}{c|}{1992} \\
\hline Butgaria & 19909 & 18728 & 12759 & 4664 & 5588 \\
dawna Czechosłowacja & 10551 & 10969 & 11532 & 11880 & 9350 \\
Wẹgry & 15390 & 17515 & 15897 & 17270 & 13618 \\
Polska & 3385 & 3405 & 3435 & 3450 & 5350 \\
Rumunia & 4597 & 5272 & 5137 & 5323 & 7100 \\
dawny ZSRR &. &. &. & \multicolumn{1}{|c|}{} & \multicolumn{1}{|c|}{. } \\
\hline
\end{tabular}

Ż r ó d I o: Yearbook of Tourism Statistics 1994, WTO.

oraz wielkość wpływów z turystyki zagranicznej. Załączone zestawienia tabelaryczne oparte są głównie na materiałach Światowej Organizacji Turystyki (WTO), do których zgłasza się wiele zastrzeżeń, przede wszystkim dotyczących zaniżonych szacunków liczby turystów i wplywów z turystyki. Dotyczy to w szczególności Polski (Poland, 1993).

Zdecydowanie najwyższy poziom rozwoju turystyki zagranicznej osiąnęły Węgry i dawna Czechosłowacja, przy czym Czechosłowacja przoduje w liczbie odwiedzających, zaś Węgry - w liczbie turystów, udzielonych noclegów i przychodów z turystyki.

$\mathrm{Na}$ początku lat 90 . wysoką trzecią pozycję $\mathrm{w}$ zestawieniach liczb bezwzględnych utraciła Bułgaria, która poza kryzysem gospodarczym najmocniej 
odczuła reorientację wyjazdów zagranicznych mieszkańców Europy Środkowej i Wschodniej. Miejsce trzecie zajął dawny Związek Radziecki traktowany łącznie. Zagraniczna turystyka przyjazdowa ma jednak w tym regionie wyraźnie stagnujący charakter.

$\mathrm{Na}$ ostatnich miejscach w tej klasyfikacji znalazly się Rumunia i Polska. W Rumunii, która przeżywa szczególne trudności polityczne, społeczne i gospodarcze, mimo dawnej orientacji na rozwój turystyki zagranicznej, turystyka przyjazdowa utrzymuje się w zasadzie na tym samym poziomie od połowy lat 80 .

Polska imponuje przede wszystkim bardzo szybkim wzrostem liczby odwiedzających, wyprzedziła pod tym względem Węgry i to może napawać optymizmem. Liczba turystów zagranicznch i udzielonych noclegów wzrasta w zdecydowanie wolniejszym tempie. Można mówić o pewnym zaniżeniu szacunków w tym zakresie przez WTO, ale i tak rozwój turystyki zagranicznej nie wypada specjalnie korzystnie. Potencjał turystyczny Polski, nawet ten postrzegany przez zachodnioeuropejskie biura podróży i przewodniki turystyczne (P i etra s z e w s k a, W y r z y k o w s k i 1993) stawia ją przecież na drugim miejscu po traktowanych łącznie krajach dawnego ZSRR.

Mocne i słabe strony Polski oraz innych krajów Europy Środkowej i Wschodniej w zakresie rozwoju turystyki zagranicznej omawiają $\mathrm{m}$. in. S. S t e c i c (1991) i L. K r e c k (1994). Wśród mocnych stron wymienia się m. in. walory historyczne i kulturowe, osobliwości przyrody, walory rekreacyjne obszarów nadmorskich, pojeziernych i górskich, walory lecznicze miejscowości uzdrowiskowych, możliwość zwiedzenia obszarów mało znanych. L. Kreck podkreśla także gościnność Polaków połączoną z dużą kulturą utrzymane mimo skomplikowanej historii. Widzi także szanse rozwoju turystyki zagranicznej w Polsce w utrzymującym się ciągle jeszcze zainteresowaniu Niemców podróżami sentymentalnymi do „swoich korzeni”, a także w odwiedzinach Polski przez polonię zagraniczną.

Do słabych stron krajów Europy Środkowej i Wschodniej, w tym Polski, należy niedostateczne zagospodarowanie na potrzeby turystyki zagranicznej, w tym nieodpowiednia baza noclegowa, niedostateczne zagospodarowanie towarzyszące, niedostateczna sieć usługowo-zaopatrzeniowa, nie satysfakcjonująca turystów zagranicznych jakość usług, niski poziom zawodowy osób pracujących w turystyce. L. Kreck podkreśla wyjątkowo niekorzystne relacje między cenami a jakością usług w polskich restauracjach, brak dostatecznej dbałości o obiekty zabytkowe, znaczny stopień zagrożenia środowiska.

Pozycje krajów Europy Środkowej i Wschodniej jako źródła międzynarodowego ruchu turystycznego zilustrowano w tabelach V-VI, które dotyczą wydatków na wyjazdy zagraniczne oraz kierunków tych wyjazdów.

Wydatki na zagraniczne wyjazdy turystyczne mieszkańców Europy Środkowej i Wschodniej są wielokrotnie niższe niż mieszkańców Europy Zachodniej i innych rozwiniętych krajów świata (tab. V). Wśród krajów Europy Środkowej 
i Wschodniej najwięcej wydają na wyjazdy zagraniczne mieszkańcy dawnej Czechosłowacji i Węgier. Polska i Rumunia ustępują tym krajom wyraźnie.

Ta be la V

Wydatki na turystykę zagraniczną mieszkańców w krajach Europy Środkowej i Wschodniej (w mln USD)

Les dépenses faites par les habitants des pays de l'Europe Centrale et de l'Est pour le tourisme à l'étranger (en milions de USD)

\begin{tabular}{|l|c|c|c|c|c|c|c|}
\hline \multirow{2}{*}{ Kraj } & \multicolumn{7}{|c|}{ Rok } \\
\cline { 2 - 8 } & 1986 & 1987 & 1988 & 1989 & 1990 & 1991 & 1992 \\
\hline Bulgaria &. &. & 74 & 113 & 189 & 128 & 23 \\
dawna Czechoslowacja & 349 & 409 & 399 & 431 & 636 & 393 & 670 \\
Węgry & 225 & 250 & 647 & 1008 & 600 & 505 & 661 \\
Polska & 186 & 203 & 251 & 215 & 220 &. &. \\
Rumunia & 22 & 30 & 33 & 35 & 103 & 143 & 260 \\
dawny ZSRR &. &. &. &. &. &. &. \\
\hline
\end{tabular}

Ź r ó d l o: Yearbook of Tourism Statistics 1992,1994, WTO.

Szczególnie widoczne jest to przy przeliczeniu wydatków na jednego mieszkańca. Brak danych o wydatkach na zagraniczne wyjazdy turystyczne mieszkańców dawnego ZSRR.

W tab. VI zaprezentowano głównie kraje docelowe turystów polskich. Wskazują one na zdecydowane obniżenie wymiany turystycznej między dawnymi krajami socjalistycznymi (z wyjątkiem przyjazdów turystów rosyjskich do Pol-

T a b e I a VI

Osiem głównych krajów docelowych turystów polskich w 1991 r. w Europie

Huit pays principaux en Europe - but de voyage des touristes polonais en 1991

\begin{tabular}{|l|c|c|c|}
\hline Kraj docelowy & $\begin{array}{c}\text { Przyjazdy } \\
\text { turystów polskich }\end{array}$ & $\begin{array}{c}\text { Zmiana procentowa } \\
1990-1991\end{array}$ & $\begin{array}{c}\text { Udzial procentowy w ogólnej li- } \\
\text { czbie turystów w kraju docelowym }\end{array}$ \\
\hline Austria & 105738 & 35,8 & 0,4 \\
Bułgaria & 361215 & $-56,5$ & 5,3 \\
Czechosłowacja & 8546482 & $-35,1$ & 13,2 \\
Niemcy & 216884 & 40,4 & 1,5 \\
Grecja & 47585 & $-22,1$ & 0,6 \\
Węgry & 1914000 & $-30,2$ & 8,8 \\
Hiszpania & 47167 & 42,9 & 0,02 \\
Turcja & 184008 & $-10,9$ & 3,3 \\
\hline
\end{tabular}

Źródło: E. S m e r a l, 1993. 
ski, głównie w celach handlowych) i znaczny wzrost wyjazdów do krajów Europy Zachodniej i Południowej.

E. S m e r a l (1993) określił zależności między udziałem w wyjazdach zagranicznych i poziomem dochodu narodowego na osobę w krajach zachodnioeuropejskich, co pozwoliło mu następnie na oszacowanie potencjalnych wyjazdów turystycznych z krajów Europy Srodkowej i Wschodniej (tab. VII). Z ana-

T a bela VII

Potencjalna intensywność i liczba podróży w Krajach Europy Środkowej i Wschodniej

L'intensité potentielle des voyages et leur nombre dans les pays de l'Europe Centrale et de l'Est

\begin{tabular}{|l|c|c|c|}
\hline \multicolumn{1}{|c|}{ Kraj } & $\begin{array}{c}\text { Ludność } \\
\text { (w mln) }\end{array}$ & $\begin{array}{c}\text { Potencjalna intensyw- } \\
\text { ność podróży (procent } \\
\text { ludności)* }\end{array}$ & $\begin{array}{c}\text { Potencjalne podróże } \\
\text { w ciaggu roku (w mln })^{*}\end{array}$ \\
\hline Bułgaria & 8,9 & 22 & 2,0 \\
dawna Czechosłowacja & 15,9 & 31 & 4,9 \\
Węgry & 10,6 & 23 & 2,4 \\
Polska & 37,8 & 17 & 6,4 \\
Rumunia & 23,3 & 12 & 2,8 \\
\hline Ogółem & 96,3 & 19 & 18,5 \\
\hline
\end{tabular}

* Podróże dłuższe niż 4 dni.

Źr ó d l o: E. S m e r a l, 1993.

T a b e la VIII

Wyjazdy zagraniczne (przekroczenia granicy) Polaków w okresie 1955-1993

Les départs des Polonais à l'étranger (les franchissements de la frontière) dans les années 1955-1993

\begin{tabular}{|c|c|}
\hline Lata & Liczba wyjazdów (przekroczeń granicy) w tys. \\
\hline 1955 & 44 \\
1960 & 216 \\
1965 & 778 \\
1970 & 871 \\
1975 & 8151 \\
1980 & 6852 \\
1985 & 3493 \\
1990 & 22131 \\
1991 & 20754 \\
1992 & 29267 \\
1993 & 31395 \\
\hline
\end{tabular}

Ź r ó d ł o: Roczniki statystyczne GUS, lata 1955-1994, Warszawa.

liz swoich wyciągną generalny wniosek, że tylko rynki Węgier, Polski i dawnej Czechosłowacji są ważne dla Europy Zachodniej. Polska ze względu na najwię- 
kszy potencjał ludnościowy, mimo niższego wskaźnika potencjalnej intensywności podróżniczej, reprezentuje największy potencjał turystyczny wyrażony liczbą $6,4 \mathrm{mln}$ podróży. W analizach nie wzięto pod uwagę krajów dawnego ZSRR.

Wyliczenia E. Smerala dotyczą dłuższych (powyżej 4 dni) wyjazdów turystycznych i można je skonfrontować z aktualnymi wielkościami przekroczeń granicy przez Polaków (tab. VIII). Sądzić można, że przy dużej ruchliwości Polaków, poprawa gospodarki krajowej i wzrost stopy życiowej ludności pozwoli zaliczyć Polskę w stosunkowo bliskiej przyszłości do krajów poważnie liczących się na europejskim rynku turystycznym.

\section{PIŚMIENNICTWO}

K r e c k L. A., 1994, Tourism in Eastern Europe: Can a Low Pricing Strategy Bring a Silver Lining, [w:] Tourism: The Economy Silver Lining,Twenty-Fifth Conference Sheraton Bal Harbour, Bal; Harbour, Florida, Travel and Tourism Research Association, Wheat Ridge, October 1994.

P i e t r a s z e w s k a E., W y r z y k ow s k i J., 1993, Touristic Attractiveness of Central and Eastern Europe in the Light of West European Touristic Guide-Books and Proposals of Tourist Agencies, [w:] Condition of the Foreign Tourism Development in the Central and Eastern Europe, University of Wrocław, Geographical Institute, Department of Regional and Tourism Geography, Department of Culture and Sport Voievodship Office of Wrocław, Wroclaw.

Poland 1992, EIU International Tourism Report, no 2.

Poland 1993, World Travel and Tourism Review.

S m e r a I E., 1993, Emerging Eastern European Tourism Markets, Tourism Management, vol. 14, no 1, February 1993.

S t e t i c S., 1991, Tourism in East Europe a New Challenge, [w:] Progress in Tourism, Recreation and Hospitality Managment, vol. 3, edited by C. P. Cooper, Belhaven Press.

W a t e r s S. R.,1993, Eastern Europe and C. I. S., [w:] Travel Industry World Yearbook. The Big Picture 1993-1994, vol. 37, Child and Waters Inc. 11.

Prof. dr hab. Jerzy Wyrzykowski

Wplynęto:

Instytut Geograficzny

Uniwersytet Wroclawski

21 października $1996 \mathrm{r}$.

pl. Uniwersytecki 1

50-137 Wroclaw 